\title{
The Issue of Migration in North East India
}

\author{
Dr Deepika Singh \\ Assistant Professor Department of Political Science Sri Venkateswara College University of Delhi \\ deepika.yashvi@gmail.com
}

Mobile no 9873495217

Northeastern India is one of the most beautiful regions, full of bio-diversity. It also boasts of vast diversity in languages and cultural practices. It is extremely significant region given its geographical proximity to China, and the Southeast through Myanmar and Bangladesh. Northeastern India is facing increased migration, leading to ethnic clashes, illegal infiltration, smuggling, terrorism. While increasing international trade is buzzword for India; fragile borders is a threat for Indian security. The migration in Northeast India is fraught with inherent contradictions. In a deprived region torn by ethnic clashes, military insurgency, illegal infiltration, poor infrastructure and massive displacement, peace has remained either elusive or transient. It has been endeavored to provide the region a new space by logistical intensification i.e. expansion of railways, construction of roads, dams and highways. These logistical developments consequently are leading to an increased demand of labour and illegal migration. The migration is very serious issue and is leading to changes in demography; threatening peace and process of development.

For instance, the Bru/Reangs in Mizoram were repeatedly targeted by the Mizos as 'outsiders' despite possessing valid documents. The Mizos affirm that 'Mizoram is for the Mizos' and not for the Reangs. The Mizos, and the militant Mizo Students Association (Mizo Zirlai Pawl) have threatened the Bru/Reangs that they should conform to the general cultural and religious standards followed in the state. This situation has been going on since the state of Mizoram was formed in 1987. The Bru/ Reangs have formed associations to protect and promote their ethnic identity, language and culture.

This paper would focus on analyzing the ethnic composition of Mizoram and its role in creating interstate dispute between Mizoram and Tripura because of exodus of Bru from Mizoram to Tripura. Further the paper would address what would be the implication of Mizo-Bru dispute on law and order situation of North East Region.

Keywords: Migration, ethnicity, displacement, infiltration, insurgency. 